ARTICLE

\title{
Nanoengineering of cathode layers for solid oxide fuel cells to achieve superior power densities
}

\author{
Katherine Develos-Bagarinao (i) ${ }^{1 凶}$, Tomohiro Ishiyama (id ${ }^{2}$, Haruo Kishimoto ${ }^{1}$, Hiroyuki Shimada (i) ${ }^{3} \&$
} Katsuhiko Yamaji ${ }^{2}$

Solid oxide fuel cells (SOFCs) are power-generating devices with high efficiencies and considered as promising alternatives to mitigate energy and environmental issues associated with fossil fuel technologies. Nanoengineering of electrodes utilized for SOFCs has emerged as a versatile tool for significantly enhancing the electrochemical performance but needs to overcome issues for integration into practical cells suitable for widespread application. Here, we report an innovative concept for high-performance thin-film cathodes comprising nanoporous $\mathrm{La}_{0.6} \mathrm{Sr}_{0.4} \mathrm{CoO}_{3-\delta}$ cathodes in conjunction with highly ordered, self-assembled nanocomposite $\mathrm{La}_{0.6} \mathrm{Sr}_{0.4} \mathrm{Co}_{0.2} \mathrm{Fe}_{0.8} \mathrm{O}_{3-\delta}$ (lanthanum strontium cobalt ferrite) and $\mathrm{Ce}_{0.9} \mathrm{Gd}_{0.1} \mathrm{O}_{2-\delta}$ (gadolinia-doped ceria) cathode layers prepared using pulsed laser deposition. Integration of the nanoengineered cathode layers into conventional anodesupported cells enabled the achievement of high current densities at $0.7 \mathrm{~V}$ reaching $\sim 2.2$ and $\sim 4.7 \mathrm{~A} / \mathrm{cm}^{2}$ at $650^{\circ} \mathrm{C}$ and $700^{\circ} \mathrm{C}$, respectively. This result demonstrates that tuning material properties through an effective nanoengineering approach could significantly boost the electrochemical performance of cathodes for development of next-generation SOFCs with high power output.

\footnotetext{
${ }^{1}$ Global Zero Emission Research Center, National Institute of Advanced Industrial Science and Technology (AIST), Tsukuba, Ibaraki, Japan. ${ }^{2}$ Research Institute for Energy Conservation, National Institute of Advanced Industrial Science and Technology (AIST), Tsukuba, Ibaraki, Japan. ${ }^{3}$ Innovative Functional Materials Research Institute, National Institute of Advanced Industrial Science and Technology (AIST), Nagoya, Aichi, Japan. ${ }^{凶}$ email: develos-bagarinao@aist.go.jp
} 
S olid oxide fuel cells (SOFCs) have attracted considerable research interest ${ }^{1-3}$ due to their high efficiencies in converting chemical energy to electricity as well as their flexibility in utilizing conventional hydrocarbon-based fuels such as methane and ammonia, and in recent years have seen a surge in the research and deployment worldwide of commercial systems ranging from stationary to transport applications. Durability and performance stability over long-term operation have been the focus of R\&D efforts in both academic and industrial sectors ${ }^{4-11}$, however, a persistent key issue required for widespread commercialization of SOFC technology is the lowering of the system cost. In addition to improving production routes and efficiency of cell stacks, improving performance by achieving higher power densities has been identified as a strategy to reduce stack size and system cost. Toward this purpose, advanced thin-film techniques such as pulsed laser deposition (PLD) have been utilized to explore alternative and nanoengineered cathode materials exhibiting high performance in terms of low area-specific resistance (ASR) and high oxygen exchange properties superior to those of conventional cathodes prepared by screen-printing techniques ${ }^{12-17}$. These studies indicate that the functionalities of existing cathode materials can be engineered at the nanoscale to specifically tailor properties required for applications. Successful implementation using the non-vacuum-based sol-gel technique has also been reported to obtain record-low values of the ASR for nanoscaled LSC $\left(\mathrm{La}_{0.6} \mathrm{Sr}_{0.4} \mathrm{CoO}_{3-\delta}\right)$ cathodes ${ }^{18}$. Nevertheless, most studies have so far only focused on the initial performance but not the long-term stability, which is considered to be one of the most crucial issues hindering the application of thin-film cathodes in practical cells. Though maintaining the stability of thin-film cathodes undoubtedly presents unique challenges as compared to conventional porous cathodes, addressing such challenges would be beneficial in developing guidelines for future fabrication processes and cell evaluation techniques.

One promising approach is to combine a conventional cathode material such as LSC or LSCF (lanthanum strontium cobalt ferrite, $\mathrm{La}_{0.6} \mathrm{Sr}_{0.4} \mathrm{Co}_{0.2} \mathrm{Fe}_{0.8} \mathrm{O}_{3-\delta}$ ) perovskite oxide with a good ionic conductor such as rare-earth-doped ceria to form nanocomposite structures $^{19}$. This has the benefit of enhancing the cathode/electrolyte interfacial area density and facilitating the oxide ion transfer, leading to a significant decrease of the polarization resistance values. It must be noted that to date only LSC-GDC (gadolinia-doped ceria, $\left.\mathrm{Ce}_{0.9} \mathrm{Gd}_{0.1} \mathrm{O}_{2-\delta}\right)^{19}$ and SSC-SDC (Srdoped $\mathrm{SmCoO}_{3}$ and $\mathrm{Sm}$-doped $\left.\mathrm{CeO}_{2}\right)^{20}$ nanocomposites have so far been reported to be successfully grown via PLD, but no similar study has yet reported the successful fabrication of nanocomposite thin films comprising LSCF and rare-earth-doped ceria. Another critical issue is how to tailor cathode nanostructures and retain active sites for oxygen reduction even at high operating temperatures. Thin-film cathodes typically suffer from an inevitable loss of nanostructures when subjected to high temperatures due to thermally induced grain coarsening ${ }^{21}$ and surface segregation ${ }^{22-25}$ occurring at such conditions, leading to significant degradation of the oxygen surface exchange properties. In addition, due to the intrinsically poor lateral conductivity of thinfilm cathodes arising from the characteristic columnar microstructure, the cell performance of these materials has not yet been fully optimized in terms of appropriately selecting current collectors which would enable good electrical contact with such nanometer-sized grains ${ }^{26,27}$.

The goal of this study is to develop advanced cathode materials with superior performance compared to conventional cathodes for the development of next-generation SOFCs. Here, we implement an innovative cell architecture utilizing at its core nanoengineered cathode layers comprising self-assembled LSCF and GDC nanocomposite thin films in conjunction with nanoporous LSC thin films. The nanoscale distribution of LSCF and GDC phases in the dense nanocomposite performs as a highly efficient transition layer by providing a high interfacial density and good adhesion with the underlying GDC interlayer, whereas the LSC thin film with its nanoporous, open structure ensures high surface area for the oxygen reduction reaction. Next, the integration of the nanoengineered cathodes in commercially viable Ni-YSZ (yttria-stabilized zirconia) anode-supported cells is demonstrated, where the roles of the respective layers in the cathode structure on the electrochemical performance are systematically examined. In the optimized cell configuration, superior electrochemical performance with high current densities at $0.7 \mathrm{~V}$ reaching $\sim 2.2$ and $\sim 4.7 \mathrm{~A} / \mathrm{cm}^{2}$ at 650 and $700^{\circ} \mathrm{C}$, respectively, are achieved.

\section{Results}

LSCF-GDC nanocomposite layer. We first focus our attention on the development of the nanocomposite layer, which forms the initial layer in direct contact with the electrolyte. To function as an effective transition layer at the electrode-electrolyte interface, nanocomposites should ideally have a fine, nanoscale-level distribution of the two phases to significantly increase the interfacial density as well as exhibit good adhesion with the electrolyte. Through an appropriate selection of PLD parameters, the resulting nanocomposite film can be finely tuned to have a nanoscale-level distribution of the LSCF and GDC phases. The LSCF-GDC nanocomposite films are revealed to be highly ordered and self-assembled in the nanoscale, as evidenced by the typical low-magnification STEM-HAADF (scanning transmission electron microscopy/high-angle annular dark-field) image (Fig. 1a) of a LSCF-GDC nanocomposite film $(\sim 300 \mathrm{~nm})$ prepared on a GDC substrate. Here, the nanocomposite film is comprised of granular domains in the order of tens of nanometers; additionally, each domain appears to contain alternately arranged LSCF and GDC nanostripes with widths in the range of $\sim 2-5 \mathrm{~nm}$ within each individual granular domain. The nanostripes exhibit long-range ordering throughout an individual granular domain spanning its entire thickness and are either oriented along the normal to the GDC substrate surface or tilted at an angle. The preferentially tilted growth direction can be ascribed to the $60^{\circ}$ incident angle of the laser beam in the design of the PLD system (as opposed to the conventional $45^{\circ}$ configuration), such that the ablated species from the target would arrive on the substrate from a slightly oblique direction. The nanostripes appear more clearly at the top region of the nanocomposite film compared to those near the interface with GDC, however, this is more likely attributed to the FIB milling process than any particular change in growth mode (due to the ion beam broadening effects, the ion-milled specimen is usually thinner at the top than at the bottom and consequently exhibits better electron transparency). Assuming that the individual phases are distributed uniformly and equally in domains of $\sim 5 \mathrm{~nm}$ each within a $\sim 300$-nm thickness, this unique self-assembled microstructure effectively increases the cathode/electrolyte interfacial area density by as high as 100 times or more, compared to a baseline sample of the same unit area where the only interface exists between two adjacent layers comprising a pure LSCF layer and GDC electrolyte.

Figure 1b shows the STEM-EDX (energy-dispersive X-ray spectroscopy) elemental mapping obtained from the area denoted by a dashed rectangle on Fig. 1a. Due to the overlapping of the La peaks with Ce in the EDX spectra, the La mapping exhibits the same pattern as that of Ce. Nevertheless, all other elements composing LSCF, namely, $\mathrm{Sr}, \mathrm{Co}$, and $\mathrm{Fe}$, congruently appear in 


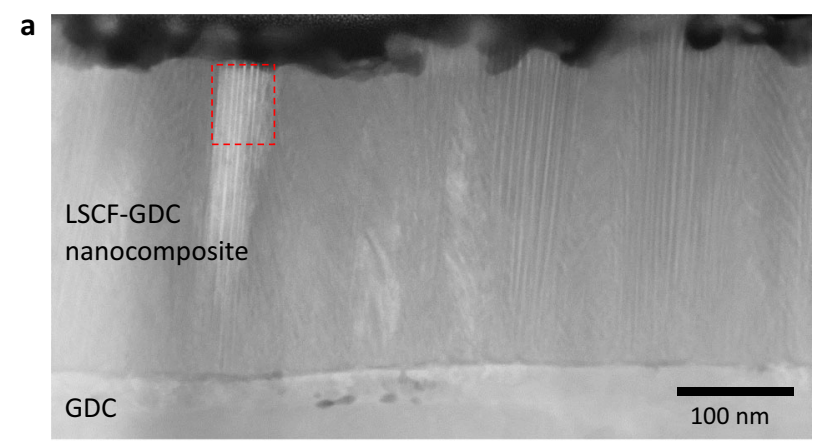

b

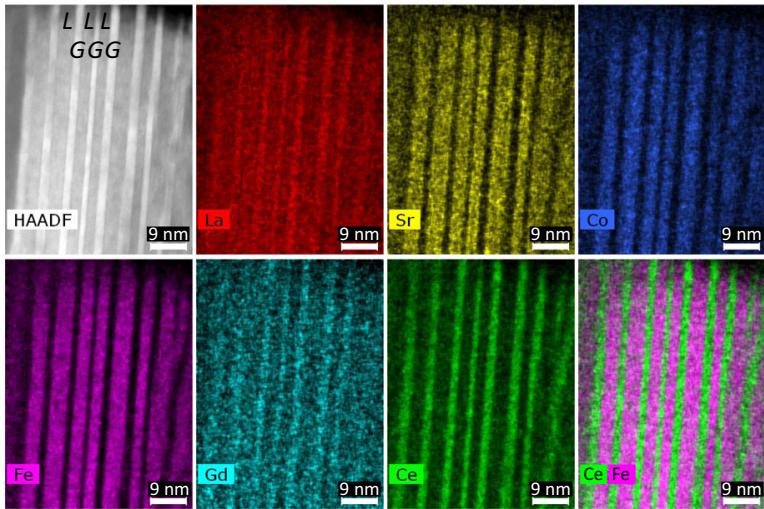

Fig. 1 Microstructure and phase distribution of the LSCF-GDC nanocomposite film. a Low-magnification STEM-HAADF image showing the existence of self-assembled nanostriped patterns with long-range ordering across the thickness of the LSCF-GDC nanocomposite film. $\mathbf{b}$ STEM-HAADF and STEM-EDX elemental distribution of the various elements comprising LSCF ( $\mathrm{La}, \mathrm{Sr}, \mathrm{Co}, \mathrm{Fe})$ and $\mathrm{GDC}(\mathrm{Gd}, \mathrm{Ce})$ phases within the area denoted by a dashed rectangle in $\mathbf{a}$. On the STEM-HAADF image, LSCF and GDC regions are denoted by the letters $L$ and $G$, respectively.

regions different from those where $\mathrm{Ce}$ and $\mathrm{Gd}$ simultaneously appear, thereby confirming the co-existence of the two different phases. From these results, it is determined that the dark-contrast nanostripes observed on the STEM-HAADF image are attributed to the LSCF phase, whereas the bright-contrast ones are attributed to the GDC phase (the heavier elements, viz. Gd and $\mathrm{Ce}$, lead to more electron scattering at higher angles). The elemental distribution depicted with $\mathrm{Fe}$ and Ce elements overlaid (bottom right) further confirms the arrangement of the LSCF and GDC phases within the nanocomposite film.

To further confirm the crystalline phases comprising the nanocomposite, additional S/TEM and selected area electron diffraction (SAED) patterns were obtained as shown in Fig. 2. Figure 2a highlights a representative granular domain showing nanostripes oriented at an angle to the substrate normal, and Fig. $2 b$ shows the corresponding SAED pattern obtained from the region denoted by a circle in Fig. 2a. Here, we can identify strong diffraction spots indexed to both LSCF and GDC, indicating the highly crystalline nature of the phases exhibiting a quasi-epitaxial relationship. Moreover, shown in Fig. $2 \mathrm{c}$ is a representative STEM-HAADF image taken from the same area confirming that the LSCF and GDC phases have formed coherent, quasi-epitaxial interfaces resulting in a remarkably high interfacial density. From additional structural evaluations using X-ray diffraction (XRD), the co-existence of LSCF and GDC phases in the nanocomposite is further corroborated by the presence of peaks attributed to either phase in the characteristic diffraction pattern. However, the peaks attributed to the LSCF phase are relatively weaker compared to those of the GDC phase, possibly due to the nature of the highly dispersed and discontinuous nanometer-sized grains of LSCF in the nanocomposite structure, in contrast to the welldefined diffraction planes normally present in single-phase LSCF thin films. Typical plan-view SEM images showed that the LSCFGDC nanocomposite is highly dense with characteristic granular features which appear to be dependent on the specific crystalline orientation of grains comprising the underlying GDC substrate. Additional data are presented in the Supplementary Information (Supplementary Fig. 1: XRD data, Supplementary Fig. 2: SEM).

Nanoporous LSC layer. For an oxygen reduction reaction to occur on cathode surfaces, it is essential that the cathode structure is sufficiently porous to fulfill the gas permeability requirement. One particular advantage of PLD is the ease with which the resultant microstructure of the film can be tuned by simply selecting the appropriate deposition parameters, for instance by selecting a parameter region with high oxygen partial pressure and low deposition temperature to obtain highly porous structures $^{28,29}$. For this purpose, LSC thin films $\sim 1 \mu \mathrm{m}$ thick are subsequently deposited on top of the dense LSCF-GDC nanocomposite layer, by selecting PLD conditions specifically to obtain nanoporous microstructures. To achieve better cathode performance, here we have selected the material LSC due to its inherently higher oxygen surface exchange property as compared to LSCF 30,31

Typical SEM images depicting the surface and cross-sectional microstructures of the as-grown LSC thin films are shown in Fig. 3a-c. Unlike the LSCF-GDC nanocomposite, which typically exhibits a dense and compact structure, the LSC thin films are comprised of nanoporous agglomerates separated by open pores or nanochannels. As the LSC thin films were deposited at room temperature, the nanostructures would invariably change due to grain coarsening when subjected to higher temperatures; nevertheless, since the as-grown film microstructure is comprised of nanocolumns which are mostly isolated from each other, this strategy seems effective in preventing the excessive grain sintering and densification which would otherwise occur for densely packed nanoscaled structures in direct contact ${ }^{18}$. This is evidenced by the representative cross-sectional SEM images in Fig. 3d, e showing the LSC thin film after an annealing treatment conducted at $700{ }^{\circ} \mathrm{C}$ in the air for $1 \mathrm{~h}$, and the assembled cathode layer comprising LSC thin film on LSCF-GDC nanocomposite prepared on GDC electrolyte (likewise heated up to $700{ }^{\circ} \mathrm{C}$ in the air) in Fig. 3f. Here, it can be observed that the LSC thin-film nanostructure evolved into clustered nanopillars comprised of grains ranging in $50-100 \mathrm{~nm}$ in size, a typical grain coarsening behavior due to sintering induced at high temperatures ${ }^{21}$. Nevertheless, despite the grain coarsening, the LSC thin film still exhibits high porosity for gas permeability as well as high surface area, which are ideal properties for facilitating oxygen reduction reaction on the cathode surfaces. Additionally, the LSC thin film exhibits good adhesion at the interface with the nanometer-sized grains of the underlying LSCF-GDC nanocomposite layer.

ASR evaluation. Electrochemical impedance spectroscopy (EIS) measurements were performed at $500-700{ }^{\circ} \mathrm{C}$ and the ASR values for symmetrical cells on GDC electrolytes are extracted from the impedance spectra. A summary of the various configurations of the symmetrical cells evaluated in this study is shown in Supplementary Table 1. For all symmetrical cell samples, the thinfilm cathodes were contacted by unsintered LSC paste which served as the current collector. In terms of microstructure, the unsintered LSC paste used in this study resembles those in related studies $^{32-34}$ which utilized finely grained in-situ activated LSC 
a

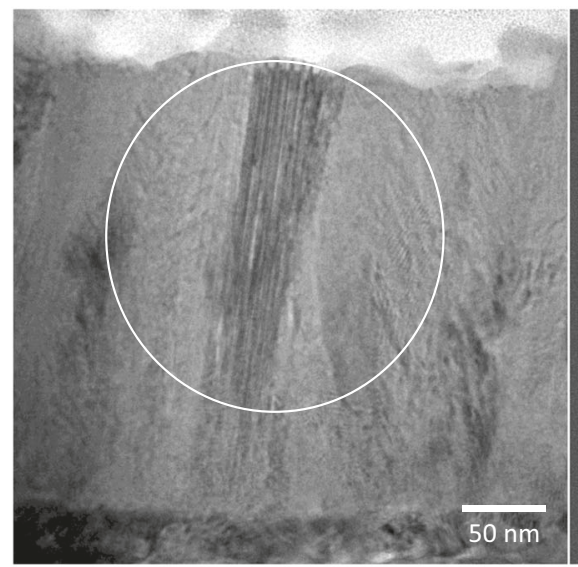

b

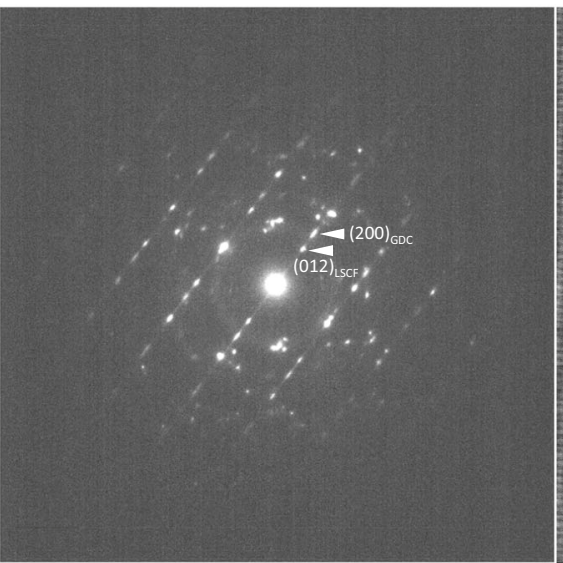

C

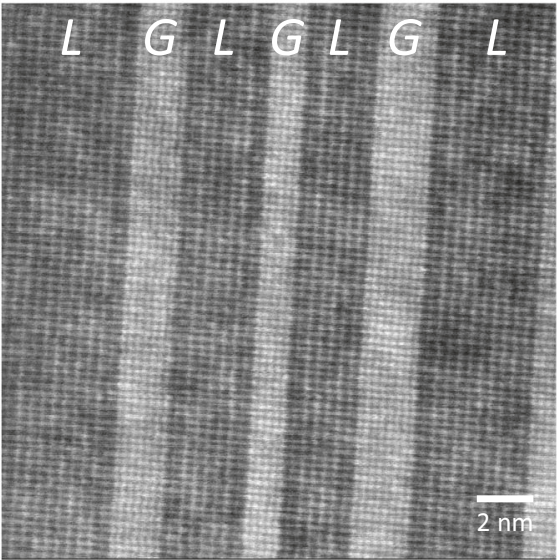

Fig. 2 Phase identification of the LSCF-GDC nanocomposite film. a Low-magnification cross-sectional TEM image depicting granular domains containing nanostripes. $\mathbf{b}$ Selected area electron diffraction (SAED) pattern of the region denoted by a circle in $\mathbf{a}$. c STEM-HAADF lattice image of the LSCF-GDC nanocomposite film, showing the coherent, quasi-epitaxial interfaces between the LSCF and GDC phases, denoted as $L$ and $G$ on the image, respectively.
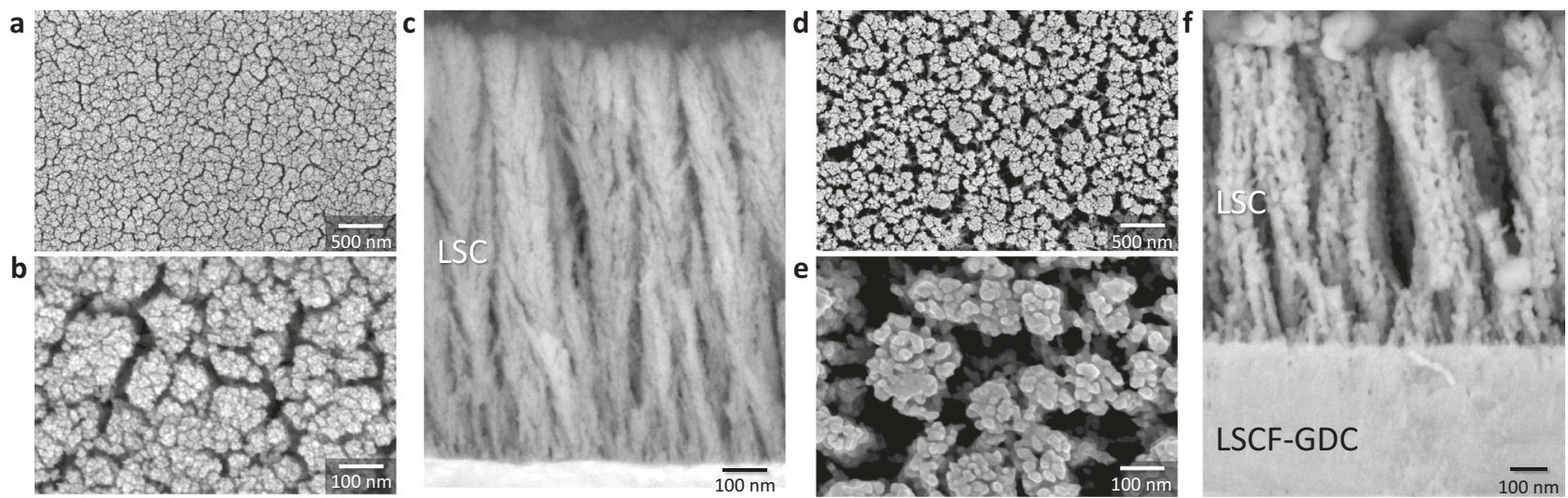

Fig. 3 Microstructural evaluation of the nanoporous LSC thin film. a Representative SEM images depicting a low-magnification view of the surface of the as-grown nanoporous LSC thin film, $\mathbf{b}$ corresponding high-magnification view of the surface, and $\mathbf{c}$ details of its cross-sectional microstructure. The typical microstructure is comprised of vertically aligned agglomerates separated by nanochannels or nanoporosities. $\mathbf{d}$, e Corresponding SEM images depicting the surface of the nanoporous LSC thin film after annealing at $700^{\circ} \mathrm{C}$ in the air for $1 \mathrm{~h}$. $f$ SEM showing the cross-section of the assembled nanoengineered cathode layer comprising the nanoporous LSC thin film on the LSCF-GDC nanocomposite.

paste as cathode, and may therefore be expected to contribute to the electrochemical activity of the cell. To understand the effect of the unsintered LSC paste, a symmetrical cell containing only this electrode (Sample 1) is also evaluated for comparison. To elucidate the effect on the performance of each layer in the nanoengineered cathode, viz., LSCF-GDC nanocomposite and nanoporous LSC, additional samples having various layer combinations were prepared on GDC electrolytes (refer to Supplementary Table 1): Sample 2 has nanoporous LSC only, Sample 3 has LSCF-GDC nanocomposite layer only, and Sample 4 contains both LSCF-GDC nanocomposite layer and nanoporous LSC. For comparison, Sample 5 is a LSCF thin film prepared using the same deposition conditions as the LSCF-GDC nanocomposite, and further combined with nanoporous LSC.

The Arrhenius plot of the ASR results for the samples is shown in Fig. 4. At $500^{\circ} \mathrm{C}$, the unsintered LSC paste (Sample 1) exhibits a relatively higher ASR value compared to the samples containing thin-film cathodes. In this intermediate temperature range, the ASR performance is considered to be dominated by oxygen exchange kinetics ${ }^{35,36}$, and given that the contribution to the electrochemical activity by the unsintered LSC paste may be considered constant among the samples similarly contacted by this material, this suggests that the improvement in performance observed for the samples containing the thin-film cathodes can therefore be attributed to the superior oxygen exchange properties of these layers. Additional improvement may also be expected due to more intimate contact of the thin films at the interface with the GDC electrolyte as compared to the case of unsintered LSC paste only. On the other hand, at $600-700{ }^{\circ} \mathrm{C}$, with the exception of Sample 4 (LSCF-GDC nanocomposite + nanoporous LSC), the performance of the unsintered LSC paste is comparable to the samples containing the nanoporous LSC (Sample 2 and Sample 5). From these results, it appears that in this temperature range the performance of the cells having the nanoporous LSC layers becomes indistinguishable from that of the unsintered LSC paste alone. One plausible explanation is that the nanoporous LSC interacts with the unsintered LSC paste as the cells are heated, which is quite expected given that this layer was prepared at room temperature and would therefore invariably change upon heating. This indicates a possible limitation on the utilization of in-situ activated cathode materials such as LSC as a current collector for electrochemical evaluation of similarly structured nanoporous cathodes at high temperatures; in this regard, alternative materials should thus be explored. 


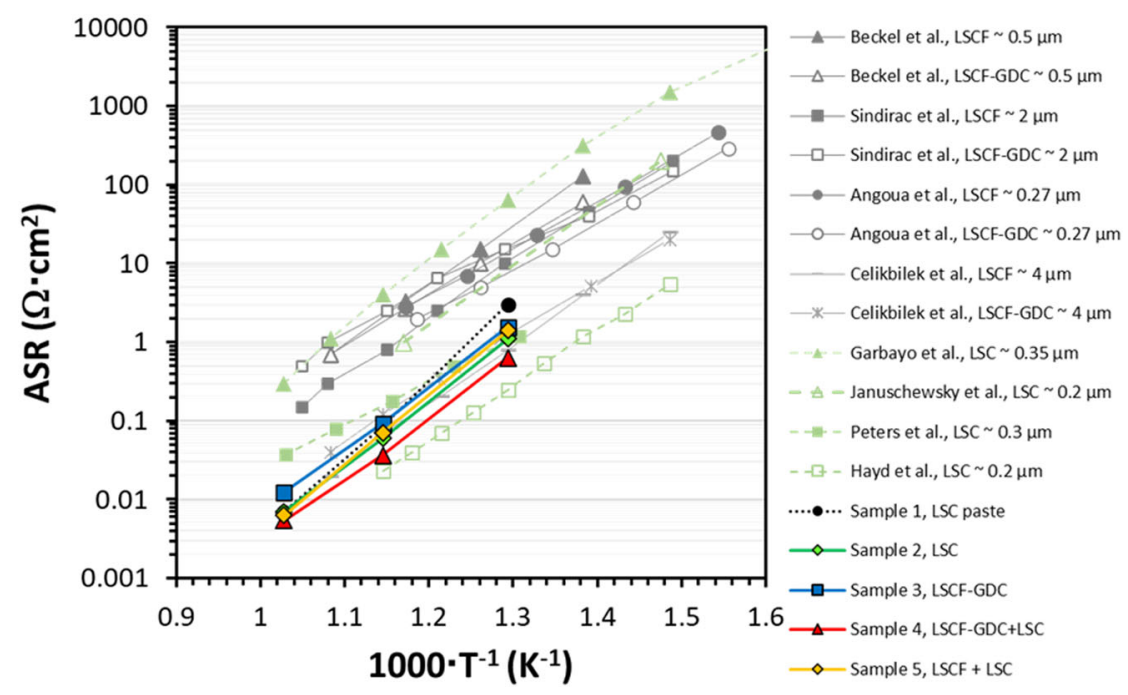

Fig. 4 Arrhenius plot of the area-specific resistance (ASR). ASR of the symmetrical cells having various configurations (refer to Supplementary Table 1) in this study are compared with values for LSC, LSCF, and LSCF-GDC nanocomposite cathodes, presented in literature ${ }^{16,37-39,52-55}$.

Nevertheless, these results indicate that introduction of nanostructured thin-film cathodes such as the ones in this study could lead to further improvement in the ASR values more especially at lower temperatures.

As shown in Fig. 4, Sample 3 (LSCF-GDC nanocomposite only) exhibits slightly higher ASR values than Sample 2 (nanoporous LSC only), which may be reasonably accounted for by its dense microstructure characterized by nanometer-sized domains and thus fewer electrode-gas phase interfaces and less intimate contact with the current collector, in contrast to that of nanoporous LSC layer. On the other hand, among the samples evaluated, Sample 4 having the combined nanoengineered cathodes (LSCF-GDC nanocomposite + nanoporous LSC) exhibits the lowest ASR values, indicating that the effective combination of the two types of layers results in superior cathode performance.

The important role of the LSCF-GDC nanocomposite as a transition layer is further confirmed from a comparison of the performance of Sample 4 with Sample 5. Here, even though both samples employ the same nanoporous LSC top layer, the utilization of the LSCF-GDC nanocomposite for Sample 4 resulted in about $50 \%$ lower ASR value $\left(\sim 36 \mathrm{~m} \Omega \mathrm{cm}^{2}\right)$ compared to the case of LSCF for Sample $5\left(\sim 70 \mathrm{~m} \Omega \mathrm{cm}^{2}\right)$ at $600{ }^{\circ} \mathrm{C}$. This proves the superiority of utilizing a layer having a structure like the LSCF-GDC nanocomposite as compared to that of a singlephase LSCF thin film as a transition layer at the interface with the GDC electrolyte. This is ascribed to the presence of a high interfacial density which boosts the oxygen diffusion and transfer across the electrode/electrolyte interface.

The electrochemical performances of the samples in this study are further compared against the reported values in the literature for several LSC, LSCF, and LSCF-GDC composite cathodes prepared by other techniques such as spray pyrolysis ${ }^{37}$, polymeric precursor $^{38}$, and electrostatic spray deposition ${ }^{39}$. Depending on the method adopted for the thin film preparation as well as film thickness, the addition of the GDC phase to the LSCF phase in the cathode structure may either have a positive or negative effect, possibly due to the combined effect of "heterogeneities in porosity within the film thickness and percolation of the ionically conducting phase ${ }^{39}$ ". Using PLD to prepare the LSCF-GDC nanocomposite (Sample 3) already results to a significant improvement in ASR values compared to those prepared by other techniques, however, further reductions in ASR values were achieved by incorporating the nanoporous LSC as well (Sample 4). The lowest ASR values obtained for the cells in this study are record-low values for LSCF-type electrodes and are competitive to the highest values reported so far for LSC-type electrodes. Refinement of the nanostructures by controlling the overall morphology and porosities is expected to further improve these values.

Anode-supported cell fabrication and characterization. Next, we demonstrate the feasibility of integrating the nanoengineered cathodes on practical cells, namely anode-supported cells prepared using conventional methods. Figure 5a shows the schematic illustration of the cell architecture developed in this study, depicting a Ni-YSZ $\left(\mathrm{Zr}_{0.85} \mathrm{Y}_{0.15} \mathrm{O}_{1.93}, 8 \mathrm{YSZ}\right)$ anode-supported cell. The Ni-YSZ substrate has a high porosity of $\sim 50 \%$ to reduce gas diffusion resistance. To achieve a pinhole-free, dense YSZ electrolyte layer on Ni-YSZ, which has a typically irregular and porous microstructure, an anode functional layer (AFL) of the same composition as the Ni-YSZ substrate but of smaller particle sizes was designed and fabricated (Fig. 5b). The AFL was prepared using NiO-YSZ nanocomposite particles synthesized via spray pyrolysis for the raw powder material. Due to the low sinterability of the nanocomposite particles obtained through the spray pyrolysis method, the fine AFL structure could be maintained even after high-temperature co-sintering. The preparation of both AFL and YSZ electrolyte layers $(\sim 2 \mu \mathrm{m})$ follows typical processing routes employed for the manufacturing of practical SOFC cells, however, for our purposes, it is of crucial importance that the GDC interlayer is likewise dense and pore-free, a goal which would be difficult to achieve using conventional screen-printing methods ${ }^{10,40}$. Studies have shown that relatively dense GDC interlayers can be prepared by adopting very high sintering temperatures, which has the disadvantage of inducing chemical interdiffusion between GDC and YSZ, leading to the formation of solid solutions with lowered conductivities ${ }^{41}$. To circumvent this issue, a dense GDC interlayer with a thickness of $\sim 2 \mu \mathrm{m}$ is prepared using PLD at intermediate temperatures without post-growth sintering. Comparison of the dense GDC interlayers with conventional porous structures and their correlation with ohmic resistance in anode-supported cells is outside the scope of the present study and will be reported in a separate publication. In addition to serving as an effective interfacial barrier, the GDC interlayer simultaneously provides a suitably 


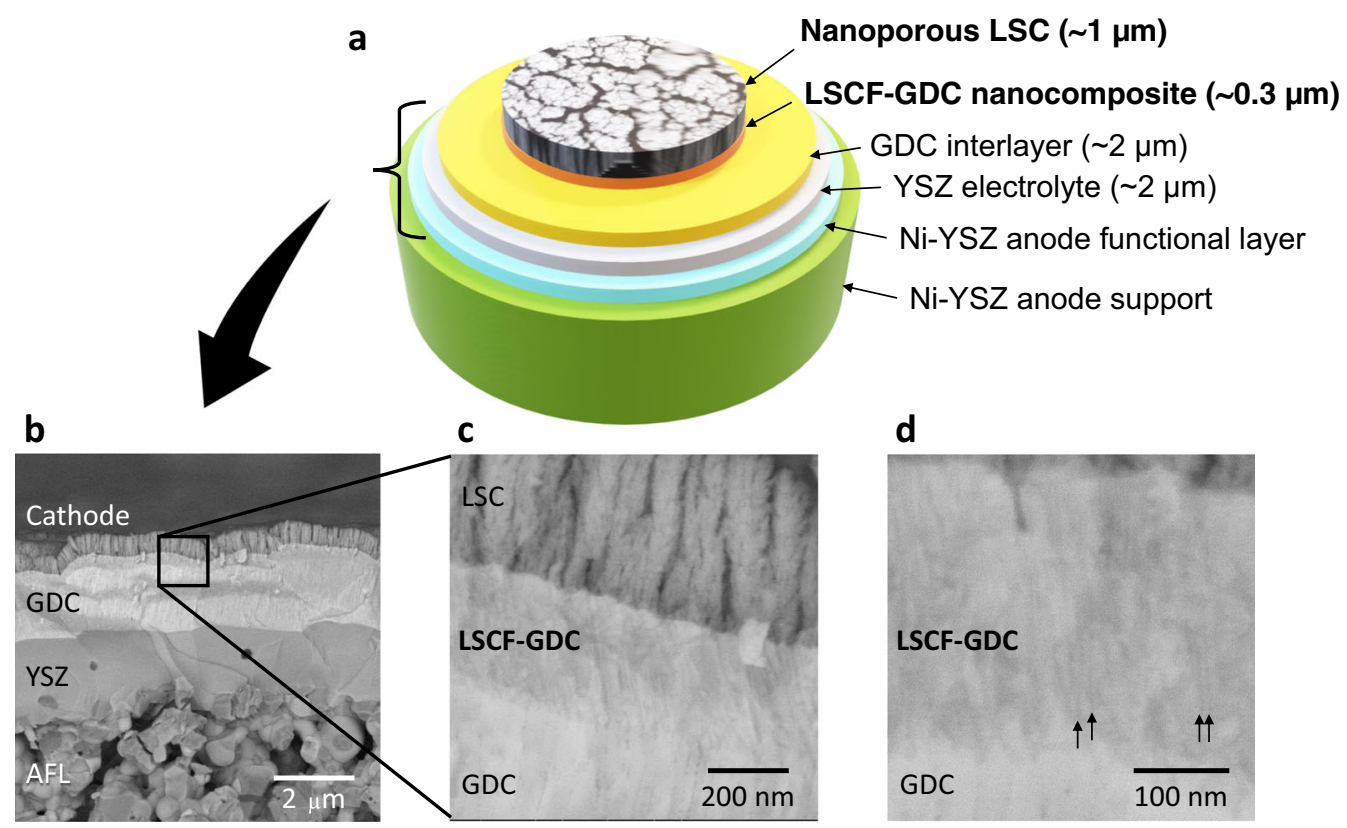

Fig. 5 Nanoengineered cell architecture and microstructural evaluation of the fabricated cell. a Schematic illustration of the nanoengineered cell architecture developed for the anode-supported cell. The anode support, AFL, and electrolyte are fabricated using conventional wet processes such as extrusion and screen-printing methods, whereas the GDC interlayer, LSCF-GDC nanocomposite layer, and nanoporous LSC thin film are all deposited using PLD. b Cross-sectional SEM image of the as-grown fabricated cell showing the details of the AFL, YSZ electrolyte, GDC interlayer, LSCF-GDC

nanocomposite layer, and nanoporous LSC thin film. c High-magnification cross-sectional SEM image (the zoomed area is depicted by a square on b) showing the detailed microstructure of the GDC interlayer, LSCF-GDC nanocomposite, and nanoporous LSC thin film. $\mathbf{d}$ High-magnification cross-sectional SEM image showing details of the LSCF-GDC nanocomposite and part of the GDC interlayer as prepared on anode-supported cell. Black arrows indicate dark-contrast stripes pertaining to the LSCF phase in the nanocomposite.

dense and homogeneous surface required for the subsequent deposition of the LSCF-GDC nanocomposite layer. As evidenced by Fig. $5 c$, the resulting dense GDC interlayer fulfills these requirements, which then enables the successful deposition of the succeeding layers. The nanoengineered cathodes were prepared using identical conditions as those employed for the symmetrical cells on GDC electrolytes, although further optimization of deposition parameters for anode-supported cells may still be explored in future studies. Finally, Fig. 5d depicts a representative high-magnification SEM image acquired in backscattered electron mode, showing the distribution of the LSCF and GDC phases which can be distinguished by the alternately bright and dark nanostripes (indicated by arrows), thereby confirming that the unique self-assembled microstructure of the LSCF-GDC nanocomposite has been successfully replicated on the anodesupported cell. Furthermore, all the PLD-deposited layers (viz. GDC interlayer, LSCF-GDC nanocomposite, and nanoporous LSC thin film) exhibit conformal growth on top of the YSZ electrolyte, which ensures uniform coverage despite the intrinsic unevenness of its surfaces. Detailed microstructural characterization of the different layers in the cell are further presented in the cross-sectional SEM images shown in Supplementary Figs. 3 and 4 , which show the completed cell right after the PLD deposition of the various layers.

Analogous to the symmetrical cells presented earlier, to elucidate the effect on the electrochemical performance of the individual cathode layers on the anode-supported cell, viz. nanoporous LSC and LSCF-GDC nanocomposite, we evaluated three cells with various configurations. Sample 6 has LSCF-GDC nanocomposite layer only, Sample 7 has nanoporous LSC only, and Sample 8 has both layers (refer to Supplementary Table 1). The cells have an active electrode area of $0.785 \mathrm{~cm}^{2}$ and were tested under a supply of $3 \%$ humidified $\mathrm{H}_{2}$ as fuel to the anode and of dry air as an oxidant to the cathode. Here, similar to that employed for symmetrical cells, unsintered LSC paste was used as the current collector. The current-voltage $(I-V)$ and current-power $(I-P)$ curves of the anode-supported cells are shown in Fig. 6. The performance was measured at temperatures ranging from 600 to $700{ }^{\circ} \mathrm{C}$. High OCV (open-circuit voltage) values of $\sim 1.1 \mathrm{~V}$, close to the theoretical value of $1.120 \mathrm{~V}$ were obtained at all temperatures. The overall trend shows that employing the LSCF-GDC nanocomposite layer alone (Sample 6) is insufficient to enhance the maximum power density compared to the one combined with nanoporous LSC and moreover, it shows the lowest performance among the samples at all temperatures evaluated. The $I-V$ dependence for this sample also shows a more prominent positive curvature at high current densities, indicating gas diffusion polarization ${ }^{42}$. This may be ascribed to the relatively dense microstructure of this layer where gas diffusion is expected to be limited. On the other hand, the nanoporous LSC layer alone (Sample 7) shows better performance than the LSCF-GDC nanocomposite alone at all temperatures; however, analogous to the results obtained for symmetrical cells, we note that it is actually the combination of both layers (Sample 8) that yields the best performance and highest maximum power output among the cells at any temperature. These results indicate that the optimum cathode performance can thus be obtained by effectively combining both nanoporous LSC and LSCF-GDC nanocomposite as cathode layers in the cell architecture.

With the goal of overcoming limitations to properly evaluate the performance of the nanoengineered cell architecture, the effect of further modifications in the measurement procedures was investigated. As the results showed earlier revealed, the use of 

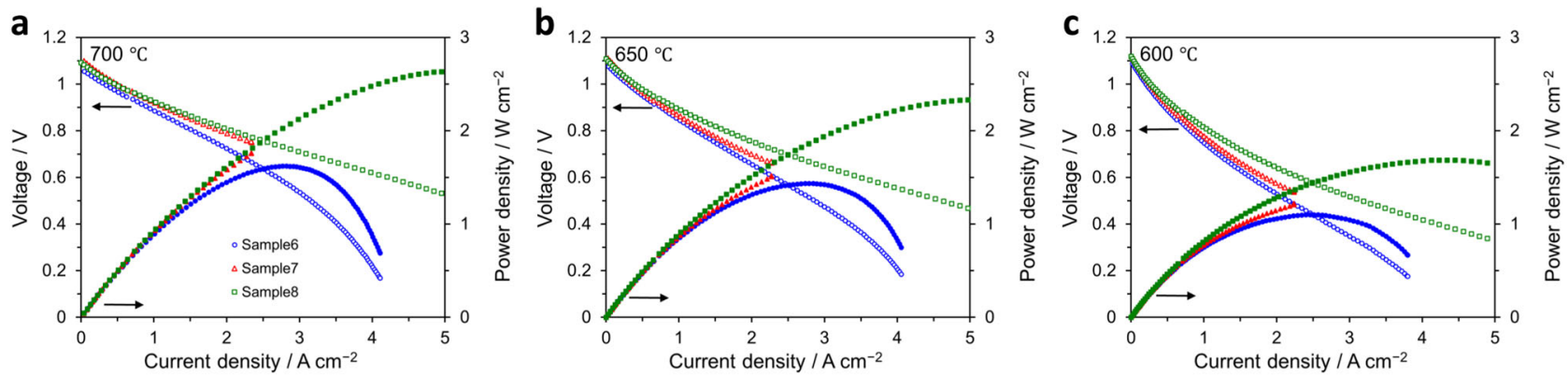

Fig. 6 Comparison of electrochemical performance of anode-supported cells. Current-voltage (I- $V)$ and current-power (I- $P$ ) curves were evaluated at a $700^{\circ} \mathrm{C}$, b $650^{\circ} \mathrm{C}$, and c $600^{\circ} \mathrm{C}$ for different anode-supported cell configurations, namely Sample 6 (LSCF-GDC, blue circles), Sample 7 (LSC, red

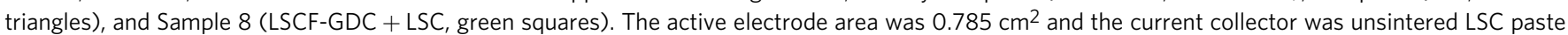
for all cells.

unsintered LSC paste as a current collector could have limited the evaluation of cell performance at higher temperatures, which then leads to the question of whether utilizing a different material for current collection would allow a more accurate evaluation of the cell. To gain a better understanding of this effect, cells of the same architecture as Sample 8 were measured using $\mathrm{Pt}$ paste as a current collector. The results are then compared as shown in Fig. 7.

The change from LSC paste (left-hand side) to Pt paste (righthand side) as current collector enabled the attainment of better performance at $700^{\circ} \mathrm{C}$, even though at lower temperatures of 650 and $600{ }^{\circ} \mathrm{C}$ the performances of the two cells are quite comparable. This does not necessarily imply that the Pt paste somehow interacted with the thin-film cathodes, leading to an apparent improvement in performance; the SEM image shown in Fig. $7 \mathrm{f}$ depicts the cross-section of the cell after testing and confirms that the Pt did not infiltrate the nanoporous LSC layer. Unlike the LSC paste, the Pt paste could be detached easily after testing, with very few residues (indicated by an arrow) located only on the surface of the nanoporous LSC, indicating no chemical interaction which could possibly affect the cathode performance. Therefore, we believe that for this case utilizing the Pt paste most likely enables a more accurate evaluation of the thin-film cathodes at higher operating temperatures. To reiterate, the main implication here is that the choice of material to be used for the current collection is and should be an important consideration for the evaluation of the performance of thin-film cathodes $^{26,27}$. In practical applications, though Pt will not likely be the material of choice due to its high cost, we believe that these results still provide useful insights into designing current collectors appropriate for use with thin-film cathodes in future studies.

To check the reproducibility of the performance shown in Fig. 7, a cell with the same configuration (Sample 9 in Supplementary Table 1) was prepared and measured on a different test rig equipped with a higher maximum current load. For this test rig, the active area was limited to $0.283 \mathrm{~cm}^{2}$; however, as the films were prepared using the same deposition conditions, a reduction in the cathode area is not expected to have a direct influence on the performance.

Figure 8 shows the electrochemical performance of the optimized cell having both nanoporous LSC and LSCF-GDC nanocomposite layers, with $\mathrm{Pt}$ paste utilized as a current collector. Similar to the evaluation for the previous samples, this sample was evaluated at different temperatures under a supply of $3 \%$ humidified $\mathrm{H}_{2}$ as fuel to the anode and of dry air as an oxidant to the cathode. Although the active electrode area was reduced for this measurement, we obtained almost similar performance in terms of area-specific ohmic resistance and polarization resistance values based on comparison with the previous cell evaluated with Pt paste (Fig. $7 b, d$ ), confirming the reproducibility of the quality of the cells irrespective of the measurement system.

As shown by the $I-V$ characteristics in Fig. $8 \mathrm{a}$, the measured $\mathrm{OCV}$ at $600^{\circ} \mathrm{C}$ is $\sim 1.1 \mathrm{~V}$, and current densities of $\sim 2.2$ and $\sim 4.7$ $\mathrm{A} / \mathrm{cm}^{2}$ under an operating voltage of $0.7 \mathrm{~V}$ at 650 and $700{ }^{\circ} \mathrm{C}$, respectively, were successfully obtained. This corresponds to power densities of $\sim 1.5$ and $\sim 3.3 \mathrm{~W} / \mathrm{cm}^{2}$, and are competitive to the highest reported values in the literature for anode-supported cells $^{43}$ or metal-supported cells ${ }^{32}$ utilizing high-performance LSC cathodes. Figure $8 \mathrm{~b}$ shows the impedance plots at $0.75 \mathrm{~V}$ and Fig. $8 \mathrm{c}$ shows the Arrhenius plot of the ASR values as determined from the impedance spectra. This cell exhibits a low ohmic resistance $R_{\mathrm{ohm}}$ of $0.026 \Omega \mathrm{cm}^{2}$ and polarization resistance $R_{\mathrm{p}}$ of $0.030 \Omega \mathrm{cm}^{2}$ under an operating condition of $0.75 \mathrm{~V}$, which are attributed to the utilization of a thin YSZ electrolyte and dense GDC interlayer, and high oxygen exchange property ascribed to the nanoengineered cathode layers, respectively. Significant reduction of these parameters enabled the attainment of superior power output for the anode-supported cells. We also evaluated the electrochemical performance of another similarly designed cell and separately measured as shown in Supplementary Fig. 5. The results showed good agreement with those shown in Fig. 8, indicating good reproducibility of our adopted nanoengineered architecture for anode-supported cells. In addition, it may be noticed that both measured $I-V$ curves exhibit a characteristic non-linear behavior that suggests either a possible activation with current density or an increase in cell temperature due to selfheating. The phenomenon of self-heating at high current densities has been reported for large cells utilizing conventional cathodes $^{32}$. However, comparison of the ohmic area-specific resistance values of the cells in this study obtained at $0.75 \mathrm{~V}$ and OCV (Supplementary Fig. 5b, c, respectively) at various temperatures do not show any significant differences, which suggest that self-heating effects are unlikely to have caused this behavior. Instead, this anomalous behavior appears to be directly correlated to the complexity of the nanostructures developed in this study, which could result in unique properties highly different from those typically exhibited by conventional cathodes. Our ongoing studies seek to elucidate the mechanisms governing this behavior through detailed analyses of the nanoengineered cathodes using advanced characterization tools and will be reported in a future publication.

Table 1 shows a summary of electrochemical performance reported in the literature for selected anode-supported cells utilizing various cathodes. Here the current density for an operating voltage of $0.7 \mathrm{~V}$ is taken as the measure of 
a

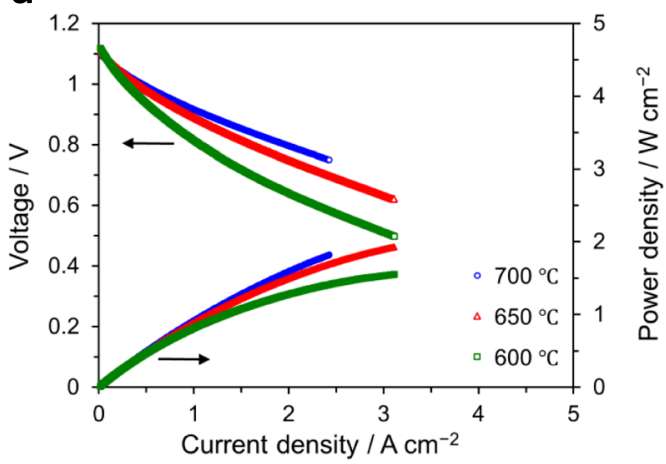

C

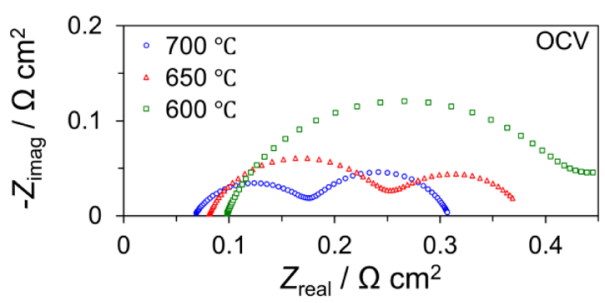

e

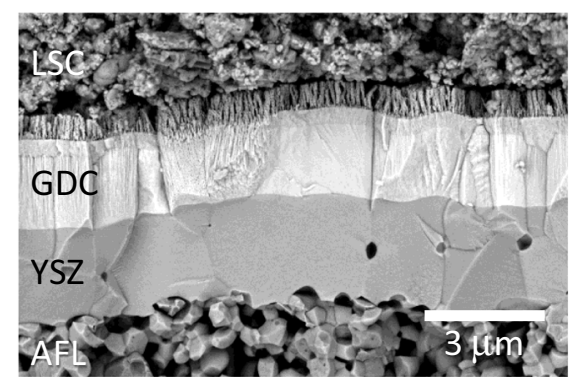

b

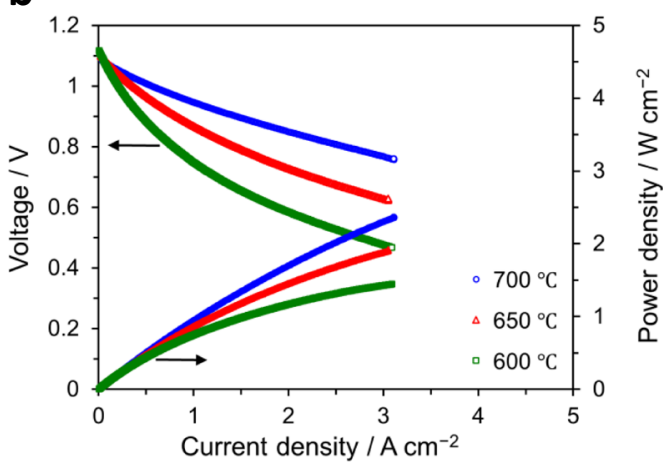

d

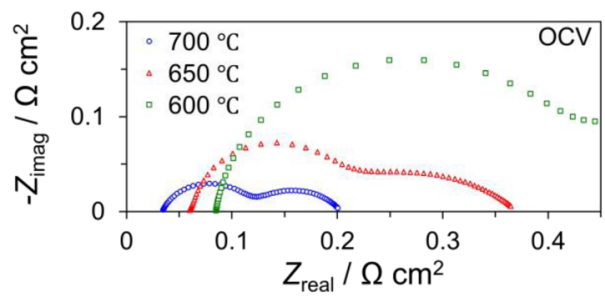

f

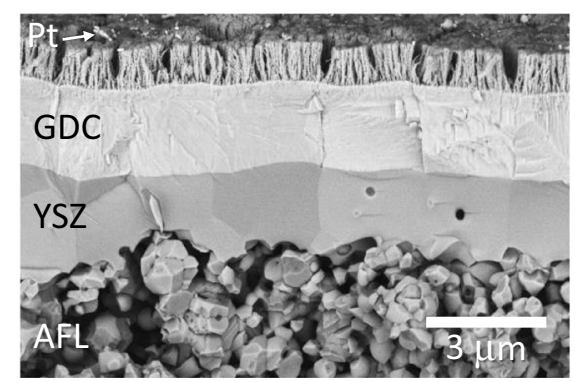

Fig. 7 Comparison of electrochemical performance and microstructure of anode-supported cells. a Current-voltage $(I-V)$ and current-power $(I-P)$ curves evaluated at various temperatures $\left(700^{\circ} \mathrm{C}\right.$ : blue circles, $650^{\circ} \mathrm{C}$ : red triangles, $600^{\circ} \mathrm{C}$ : green squares) of the anode-supported cells utilizing nanoengineered cathode layers comprised of nanoporous LSC and LSCF-GDC nanocomposite (Sample 8 configuration, see Supplementary Table 1) and tested using different current collectors. LSC paste was utilized for the cell on the left-hand side, whereas Pt paste was used for the one on the right-hand side. The current load is limited to $3 \mathrm{~A} / \mathrm{cm}^{2}$. The performance at $700{ }^{\circ} \mathrm{C}$ for the cell tested with $\mathrm{LSC}$ paste is inferior compared to the one where Pt paste was used; however, their performances are comparable at lower temperatures $\left(650\right.$ and $\left.600^{\circ} \mathrm{C}\right)$. These results suggest that the material used for the current collection is an important consideration when evaluating the electrochemical performance. The active electrode area for both cells is $0.785 \mathrm{~cm}^{2}$. c, $\mathbf{d}$ Corresponding impedance spectra at OCV and various temperatures. e, $\mathbf{f}$ Representative cross-sectional SEM images showing the cells after testing using LSC paste (e) and Pt paste (f) as current collectors.

electrochemical performance. The performance of cells utilizing the nanoengineered cathode layers developed in this study is about a factor of three higher than the top-performing LSCFGDC composite cathodes on anode-supported cells reported in the literature (cf. performance at $700{ }^{\circ} \mathrm{C}$, Park et al. ${ }^{44}$ ) and outperforms that recorded to date for a thin-film composite electrode by about $20 \%$ (cf. SSC-SDC composites on LSGM, Kang et $\mathrm{al}^{20}$ ) at the operating temperature of $700^{\circ} \mathrm{C}$. The superior performance of our cell is attributed to the combination of the following reasons: first and foremost, the enhanced cathode performance resulting in very low ASR as facilitated by the combined nanoporous LSC thin film and highly ordered selfassembly of LSCF and GDC in the nanocomposite layer, and next, its successful integration via the nanoengineered cell architecture adopted in the fabrication of the cell, which among others employs a relatively thin YSZ electrolyte and a dense GDC interlayer which effectively eliminates the need for post-growth sintering. In this configuration, we can therefore harness the superior electrochemical performance of the thin-film cathodes and achieve high power densities which could not be easily attained with conventional, micrometer-scaled cathode structures. For industrial-scale applications, large-area PLD or sputtering systems with capabilities of depositing on substrates with sizes of 8 inches in diameter or more are already commercially available ${ }^{45}$ and can be utilized to fabricate similar nanoengineered cathodes on several large-area substrates in batch processes. Due to the potential of achieving significantly higher power densities over relatively smaller areas, it would also be possible to develop more compact devices by utilizing nanoengineered thin-film cathodes. Moreover, the proposed cell architecture can be readily adapted to smallerscale micro-SOFC devices, in combination with metal substrates and other low-cost, practical materials. The results presented here mark an important first step in the development of similarly designed innovative materials for high-performance SOFC devices.

Lastly, as a preliminary test to evaluate the cell performance over time, the voltage was measured at a constant current of $1 \mathrm{~A} /$ 

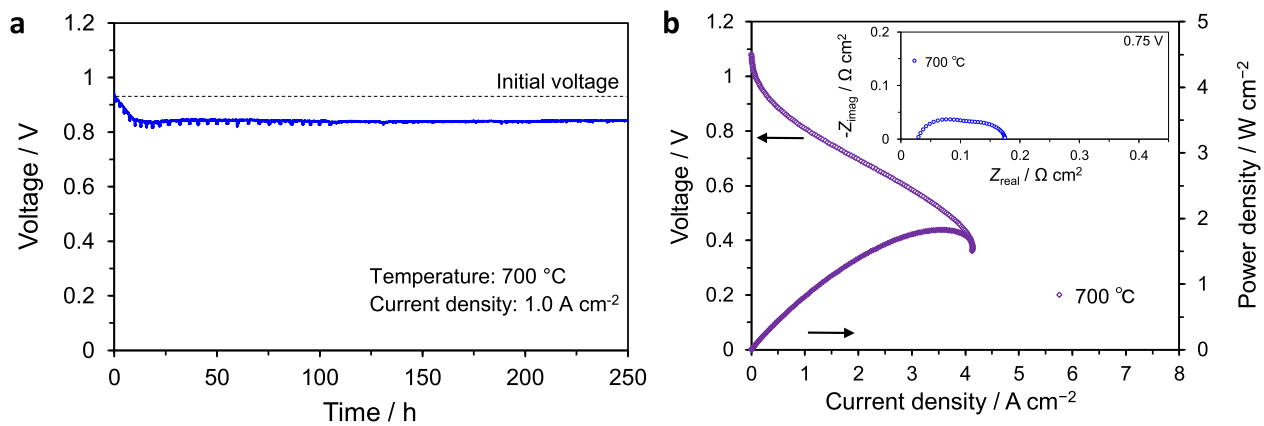

Fig. 9 Evaluation of cell performance with time. a Time-dependence of the voltage at an applied current density of $1 \mathrm{~A} / \mathrm{cm}^{2}$ at $700{ }^{\circ} \mathrm{C}$. b Current-voltage $(I-V)$ and current-power $(I-P)$ curves evaluated at $700^{\circ} \mathrm{C}$ at the end of the durability test. Inset shows the final impedance spectra obtained at $0.75 \mathrm{~V}$ and $700^{\circ} \mathrm{C}$.

GDC phases. The combination of these two layers in the cathode structure resulted in superior cathode performance with very low ASR values competitive to the highest values reported in the literature. The nanoengineered cathode layers were successfully integrated into conventional anode-supported cells, whereby the utilization of a relatively thin YSZ electrolyte in combination with a dense GDC interlayer, facilitates significant reduction in the cell's ohmic resistance complementary to the superior cathode performance. Consequently, anode-supported cells utilizing the nanoengineered cathodes demonstrate superior cell performance in terms of high current densities at $0.7 \mathrm{~V}$ achieving $\sim 2.2$ and $\sim 4.7 \mathrm{~A} / \mathrm{cm}^{2}$ at $6500^{\circ} \mathrm{C}$ and $700{ }^{\circ} \mathrm{C}$, representing a significant improvement of performance compared to hitherto reported cells utilizing thin-film cathodes. Further work is ongoing to fine-tune the cell architecture, optimize the fabrication process, and elucidate the factors affecting long-term performance stability. These advancements are expected to pave the way towards applications in next-generation SOFCs.

\section{Methods}

Film growth. The LSCF-GDC nanocomposite thin films were grown via a simple one-step process using a PLD system (NanoPLD, PVD Products). A polycrystalline target consisting of LSCF and GDC $\left(10 \mathrm{~mol} \% \mathrm{Gd}_{2} \mathrm{O}_{3}\right)$ sectors with an areal ratio of 3:1 was ablated by a $\mathrm{KrF}$ excimer laser ( $248 \mathrm{~nm}$ wavelength, COMPexPro 102, Coherent) with laser energy of $200 \mathrm{~mJ}$ and repetition rate of $10 \mathrm{~Hz}$. The samples were heated at $750^{\circ} \mathrm{C}$ at $5 \mathrm{~Pa}$ oxygen pressure and after film deposition were chamber-cooled to room temperature under the same atmosphere. GDC thin films as interlayers were prepared using the same deposition conditions as the LSCFGDC nanocomposite thin films, with the desired thickness obtained by increasing the number of laser pulses. LSC thin films were grown using LSC ceramic targets ablated with laser energy of $275 \mathrm{~mJ}$ and repetition rate of $20 \mathrm{~Hz}$ at room temperature and 13.3 $\mathrm{Pa}$ oxygen pressure, and the number of laser pulses was adjusted to achieve a final thickness of $\sim 1 \mu \mathrm{m}$. Identical deposition conditions were adopted for the preparation of cathode layers on both symmetrical cells and anodesupported cells. Supplementary Table 1 shows the summary of all the samples prepared in this study.

Characterization. Microstructural characterization was performed using a fieldemission scanning electron microscope (SEM, NovaNanoSEM 450, FEI) in secondary electron and backscattered electron mode, and transmission electron microscope (TEM, Tecnai Osiris, FEI) operated at $200 \mathrm{kV}$ in scanning TEM mode (STEM). Energy-dispersive X-ray spectroscopy (EDX) measurements were performed in the same instrument. Cross-sectional samples for S/TEM characterization were prepared using a dual-beam FIB-SEM (focused ion beam, Scios, FEI) equipped with $\mathrm{Ga}^{+}$ion source, operated with a maximum acceleration voltage of $30 \mathrm{kV}$ and final thinning performed at $<3 \mathrm{kV}$. For further thinning and to reduce the damage from the FIB milling, additional milling was performed using an argon ion milling machine (Gatan PIPS 691 precision ion polishing system) operated at room temperature.

For the electrochemical impedance measurement of symmetrical cells, an unsintered LSC paste consisting of fine particles ranging from hundreds of $\mathrm{nm}$ to $\sim 1 \mu \mathrm{m}$ in sizes was applied to the samples using the screen-printing method, allowed to dry at $100^{\circ} \mathrm{C}$ inside a drying oven for $12-24 \mathrm{~h}$, afterward gold mesh was pressed as a contact. The active electrode area was $0.785 \mathrm{~cm}^{2}$. Electrochemical impedance spectra were recorded with a Versastat4 (Princeton Applied Research, USA) frequency response analyzer in a frequency range of $1 \mathrm{MHz}$ to $0.1 \mathrm{~Hz}$ from 500 to $700^{\circ} \mathrm{C}$ in flowing air $(50 \mathrm{ml} / \mathrm{min})$. The impedance data were analyzed and fitted using the Zview software.

Anode-supported cell fabrication. NiO powder (Sumitomo Metal Mining Co.), YSZ powder (TZ-8Y, Tosoh) at a weight ratio of 60:40 were mixed with pore former and binder, and then the powder mixture was stirred in a vacuum chamber with the addition of a proper amount of distilled water. After aging the mixture in an ambient atmosphere for $15 \mathrm{~h}$, the mixture was formed into a NiO-YSZ green sheet by an extrusion process where a metal mold $(0.7-\mathrm{mm}$ thick, 120 -mm wide) was used. The detailed fabrication procedure of the extrusion process has been presented elsewhere ${ }^{46}$. Button-size pieces (32-mm diameter) cut from the NiO-YSZ green sheet were sintered at $1240^{\circ} \mathrm{C}$ for $2 \mathrm{~h}$ in air. The NiO-YSZ paste for the AFL was prepared by mixing NiO-YSZ nanocomposite particles synthesized by spray pyrolysis with $\alpha$-terpineol (Kanto Chemical Co.), ethyl cellulose (45 cP, Kishida Chemical Co.), dispersant, and plasticizer. The YSZ paste for the electrolyte layer was also prepared by mixing YSZ powder (TZ-8Y, Tosoh) and the same admixtures as in the $\mathrm{NiO}$-YSZ paste. On the sintered $\mathrm{NiO}$-YSZ pieces, the $\mathrm{NiO}-\mathrm{YSZ}$ paste and YSZ paste were screen-printed in succession, and then the coated pieces were co-sintered at $1360^{\circ} \mathrm{C}$ for $3 \mathrm{~h}$ in air, resulting in electrolyte/anode half-cells $(\sim 22$ $\mathrm{mm}$ in diameter) with a NiO-YSZ AFL. To complete the cell, the GDC interlayer, LSCF-GDC nanocomposite, and nanoporous LSC thin films were deposited using the PLD technique with deposition conditions as described above.

Anode-supported cell performance measurements. For Samples 6, 7, and 8, current-voltage $(I-V)$ and EIS measurements were performed for the anodesupported cells at $600-700{ }^{\circ} \mathrm{C}$ using $3 \%$ humidified $\mathrm{H}_{2}$ as fuel at a flow rate of 200 $\mathrm{mL} / \mathrm{min}$ and ambient air as oxidant at a flow rate of $200 \mathrm{~mL} / \mathrm{min}$ by sealing with pyrex glass ring. A potentiostat/galvanostat with a frequency response analyzer (VSP-300 with $10 \mathrm{~A} / 5 \mathrm{~V}$ booster board, Biologic) was used for these measurements. In EIS, the frequency range was $1 \mathrm{MHz}$ to $0.1 \mathrm{~Hz}$ and the amplitude of applied voltage was $10 \mathrm{mV}$. For the current collection, unsintered LSC paste similar to that utilized for symmetrical cells was painted on the top surfaces of the cathode, and nickel foam contacted the anode. The operating temperature was monitored using a thermocouple located in proximity $(\sim 1 \mathrm{~mm})$ to the anode surface. A schematic illustration of the electrochemical test set-up is shown in Supplementary Fig. 6.

For Sample 9 and other samples with a similar configuration, $I-V$ and EIS measurements were performed in a different test bench for the anode-supported cells at $550-700{ }^{\circ} \mathrm{C}$ using $3 \%$ humidified $\mathrm{H}_{2}$ as fuel at a flow rate of $70 \mathrm{~mL} / \mathrm{min}$ and ambient air as oxidant at a flow rate of $140 \mathrm{~mL} / \mathrm{min}$. A potentiostat/galvanostat with a frequency response analyzer (Autolab PGSTAT302, Metrohm) was used for these measurements. In EIS, the frequency range was $1 \mathrm{MHz}$ to $0.1 \mathrm{~Hz}$ and the amplitude of applied voltage was $10 \mathrm{mV}$. For the current collection, unsintered $\mathrm{Pt}$ paste was painted on the top surfaces of both cathode and anode. The operating temperature was monitored using a thermocouple located in proximity $(\sim 1 \mathrm{~mm})$ to the cathode surface.

\section{Data availability}

The data that support the findings of this study are available from the authors on reasonable request, see author contributions for specific data sets.

Received: 19 November 2020; Accepted: 1 June 2021; Published online: 25 June 2021 


\section{References}

1. Yokokawa, H. et al. Recent achievements of NEDO durability project with an emphasis on correlation between cathode overpotential and ohmic loss. Fuel Cells 17, 473-497 (2017).

2. Irvine, J. T. S. et al. Evolution of the electrochemical interface in hightemperature fuel cells and electrolysers. Nat. Energy 1, 15014 (2016).

3. Zhang, X. et al. A review of integration strategies for solid oxide fuel cells. J. Power Sources 195, 685-702 (2010).

4. Hara, D. Toward a Hydrogen Society - introduction of representative projects in Japan. ECS Trans. 91, 3-7 (2019).

5. Tsimis, D., Aguilo-Rullan, A., Atanasiu, M., Zafeiratou, E. \& Dirmiki, D. The Status of SOFC and SOEC R\&D in the European Fuel Cell and Hydrogen Joint Undertaking Programme. ECS Trans. 91, 9-26 (2019).

6. Vora, S. D., Jesionowski, G. \& Williams, M. C. Overview of U.S. Department of Energy Office of Fossil Energy's Solid Oxide Fuel Cell Program for FY2019. ECS Trans. 91, 27-39 (2019).

7. Leah, R. T. et al. Latest results and commercialization of the ceres power steelcell technology platform. ECS Trans. 91, 51-61 (2019).

8. Noponen, M. et al. Elcogen - next generation solid oxide cell and stack technology. ECS Trans. 91, 91-97 (2019)

9. Laurencin, J. et al. Degradation mechanism of $\mathrm{La}_{0.6} \mathrm{Sr}_{0.4} \mathrm{Co}_{0.2} \mathrm{Fe}_{0.8} \mathrm{O}_{3-\delta} /$ $\mathrm{Gd}_{0.1} \mathrm{Ce}_{0.9} \mathrm{O}_{2-\delta}$ composite electrode operated under solid oxide electrolysis and fuel cell conditions. Electrochim. Acta 241, 459-476 (2017).

10. Szasz, J. et al. Nature and functionality of $\mathrm{La}_{0.58} \mathrm{Sr}_{0.4} \mathrm{Co}_{0.2} \mathrm{Fe}_{0.8} \mathrm{O}_{3-\delta} /$ $\mathrm{Gd}_{0.2} \mathrm{Ce}_{0.8} \mathrm{O}_{2-\delta} / \mathrm{Y}_{0.16} \mathrm{Zr}_{0.84} \mathrm{O}_{2-\delta}$ Interfaces in SOFCs. J. Electrochem. Soc. 165, F898-F906 (2018).

11. Menzler, N. H., Sebold, D., Sohn, Y. J. \& Zischke, S. Post-test characterization of a solid oxide fuel cell after more than 10 years of stack testing. J. Power Sources 478, 228770 (2020).

12. Celikbilek, O. et al. Enhanced catalytic activity of nanostructured, A-site deficient $\left(\mathrm{La}_{0.7} \mathrm{Sr}_{0.3}\right)_{0.95}\left(\mathrm{Co}_{0.2} \mathrm{Fe}_{0.8}\right) \mathrm{O}_{3-\delta}$ for SOFC cathodes. J. Mater. Chem. A 7, 25102-25111 (2019).

13. Sase, $\mathrm{M}$. et al. Enhancement of oxygen exchange at the hetero interface of ( $\mathrm{La}$ $\mathrm{Sr}) \mathrm{CoO}_{3} /(\mathrm{La}, \mathrm{Sr})_{2} \mathrm{CoO}_{4}$ in composite ceramics. Solid State Ion. 178, 1843-1852 (2008).

14. Develos-Bagarinao, K., Budiman, R. A., Ishiyama, T., Yamaji, K. \& Kishimoto, $\mathrm{H}$. Leveraging catalytic effects of heterointerfaces through multilayering for superior cathode performance. J. Power Sources 480, 229094 (2020).

15. Develos-Bagarinao, K. et al. Multilayered LSC and GDC: An approach for designing cathode materials with superior oxygen exchange properties for solid oxide fuel cells. Nano Energy 52, 369-380 (2018).

16. Januschewsky, J., Ahrens, M., Opitz, A., Kubel, F. \& Fleig, J. Optimized $\mathrm{La}_{0.6} \mathrm{Sr}_{0.4} \mathrm{CoO}_{3-\delta}$ thin-film electrodes with extremely fast oxygen-reduction kinetics. Adv. Funct. Mater. 19, 3151-3156 (2009).

17. Aidhy, D. S. \& Weber, W. J. Microstructure design for fast oxygen conduction. J. Mater. Res. 31, 2-16 (2016).

18. Hayd, J., Dieterle, L., Guntow, U., Gerthsen, D. \& Ivers-Tiffée, E. Nanoscaled $\mathrm{La}_{0.6} \mathrm{Sr}_{0.4} \mathrm{CoO}_{3-\delta}$ as intermediate temperature solid oxide fuel cell cathode: microstructure and electrochemical performance. J. Power Sources 196 7263-7270 (2011).

19. Yoon, J. et al. Vertically aligned nanocomposite thin films as a cathode/ electrolyte interface layer for thin-film solid oxide fuel cells. Adv. Funct. Mater. 19, 3868-3873 (2009).

20. Kang, B. S., Matsuda, J., Ju, Y. W., Kim, H. H. \& Ishihara, T. Nano strain induced double columnar oxide as highly active oxygen-dissociation electrode for Ni-Fe metal supported solid oxide fuel cells. Nano Energy 56, 382-390 (2019).

21. Shah, M., Voorhees, P. W. \& Barnett, S. A. Time-dependent performance changes in LSCF-infiltrated SOFC cathodes: the role of nano-particle coarsening. Solid State Ion. 187, 64-67 (2011).

22. Chen, Y. et al. Segregated chemistry and structure on (001) and (100) surfaces of $\left(\mathrm{La}_{1-x} \mathrm{Sr}_{x}\right)_{2} \mathrm{CoO}_{4}$ override the crystal anisotropy in oxygen exchange kinetics. Chem. Mater. 15, 5436-5450 (2015).

23. Tsvetkov, N., Lu, Q., Sun, L., Crumlin, E. J. \& Yildiz, B. Improved chemical and electrochemical stability of perovskite oxides with less reducible cations at the surface. Nat. Mater. 15, 1010-1017 (2016).

24. Develos-Bagarinao, $\mathrm{K}$. et al. Oxygen surface exchange properties and surface segregation behavior of nanostructured $\mathrm{La}_{0.6} \mathrm{Sr}_{0.4} \mathrm{Co}_{0.2} \mathrm{Fe}_{0.8} \mathrm{O}_{3-\delta}$ thin film cathodes. Phys. Chem. Chem. Phys. 21, 7183-7195 (2019).

25. Koo, B. et al. Sr segregation in perovskite oxides: why it happens and how it exists. Joule 2, 1476-1499 (2018)

26. Noh, H. S. et al. Optimization of current collection to reduce the lateral conduction loss of thin-film-processed cathodes. J. Power Sources 230, 109-114 (2013).

27. Son, J. W. \& Song, H. S. Influence of current collector and cathode area discrepancy on performance evaluation of solid oxide fuel cell with thin-filmprocessed cathode. Int. J. Precis. Eng. Manuf. Green. Technol. 1, 313-316 (2014).
28. Plonczak, P. et al. Tailoring of $\mathrm{La}_{x} \mathrm{Sr}_{1-x} \mathrm{Co}_{y} \mathrm{Fe}_{1-y} \mathrm{O}_{3-\delta}$ nanostructure by pulsed laser deposition. Adv. Funct. Mater. 21, 2764-2775 (2011)

29. Infortuna, A., Harvey, A. S. \& Gauckler, L. J. Microstructures of CGO and YSZ thin films by pulsed laser deposition. Adv. Funct. Mater. 18, 127-135 (2008).

30. Berenov, A. V., Atkinson, A., Kilner, J. A., Bucher, E. \& Sitte, W. Oxygen tracer diffusion and surface exchange kinetics in $\mathrm{La}_{0.6} \mathrm{Sr}_{0.4} \mathrm{CoO}_{3-\delta}$. Solid State Ion. 181, 819-826 (2010).

31. Armstrong, E. N., Duncan, K. L., Oh, D. J., Weaver, J. F. \& Wachsman, E. D. Determination of surface exchange coefficients of LSM, LSCF, YSZ, GDC constituent materials in composite SOFC cathodes. J. Electrochem. Soc. 158 B492 (2011).

32. Udomsilp, D. et al. Metal-supported solid oxide fuel cells with exceptionally high power density for range extender systems. Cell Rep. Phys. Sci. 1, 100072 (2020).

33. Udomsilp, D. et al. High-performance metal-supported solid oxide fuel cells by advanced cathode processing. J. Electrochem. Soc. 164, F1375-F1384 (2017).

34. Udomsilp, D. et al. Dual-phase cathodes for metal-supported solid oxide fuel cells: processing, performance, durability. J. Electrochem. Soc. 166, F506-F510 (2019).

35. Prestat, $M$. et al. Oxygen reduction at thin dense $\mathrm{La}_{0.52} \mathrm{Sr}_{0.48} \mathrm{Co}_{0.18} \mathrm{Fe}_{0.82} \mathrm{O}_{3-\delta}$ electrodes: Part II: Experimental assessment of the reaction kinetics. $J$. Electroceram. 18, 111-120 (2007)

36. Baumann, F. S., Fleig, J., Habermeier, H. U. \& Maier, J. Impedance spectroscopic study on well-defined $(\mathrm{La}, \mathrm{Sr})(\mathrm{Co}, \mathrm{Fe}) \mathrm{O}_{3-\delta}$ model electrodes. Solid State Ion. 177, 1071-1081 (2006).

37. Beckel, D. et al. Electrochemical performance of LSCF based thin film cathodes prepared by spray pyrolysis. Solid State Ion. 178, 407-415 (2007).

38. Sindiraç, C. et al. Fabrication of LSCF and LSCF-GDC nanocomposite thin films using polymeric precursors. Ionics 26, 913-925 (2020).

39. Çelikbilek, Özden et al. Rational design of hierarchically nanostructured electrodes for solid oxide fuel cells. J. Power Sources 333, 72-82 (2016).

40. Wankmüller, F. et al. Correlative tomography at the cathode/electrolyte interfaces of solid oxide fuel cells. J. Power Sources 360, 399-408 (2017)

41. Zhou, X. D., Scarfino, B. \& Anderson, H. U. Electrical conductivity and stability of Gd-doped ceria/Y-doped zirconia ceramics and thin films. Solid State Ion. 175, 19-22 (2004).

42. Wachsman, E. D. \& Singhal, S. C. Solid oxide fuel cell commercialization, research, and challenges. Electrochem. Soc. Interface 18, 38-43 (2009).

43. Han, F. et al. Novel high-performance solid oxide fuel cells with bulk ionic conductance dominated thin-film electrolytes. J. Power Sources 218, 157-162 (2012).

44. Park, B. K. \& Barnett, S. A. Boosting solid oxide fuel cell performance: Via electrolyte thickness reduction and cathode infiltration. J. Mater. Chem. A 8 11626-11631 (2020).

45. Greer, J. Pulsed Laser Deposition of Thin Films Ch. 9 (John Wiley \& Sons, Inc. USA, 2007).

46. Shimada, $\mathrm{H}$. et al. Challenge for lowering concentration polarization in solid oxide fuel cells. J. Power Sources 302, 53-60 (2016).

47. Sumi, H., Yamaguchi, T., Hamamoto, K., Suzuki, T. \& Fujishiro, Y. High performance of $\mathrm{La}_{0.6} \mathrm{Sr}_{0.4} \mathrm{Co}_{0.2} \mathrm{Fe}_{0.8} \mathrm{O}_{3}-\mathrm{Ce}_{0.9} \mathrm{Gd}_{0.1} \mathrm{O}_{1.95}$ nanoparticulate cathode for intermediate temperature microtubular solid oxide fuel cells. J. Power Sources 226, 354-358 (2013).

48. Leng, Y., Chan, S. H. \& Liu, Q. Development of LSCF-GDC composite cathodes for low-temperature solid oxide fuel cells with thin film GDC electrolyte. Int. J. Hydrog. Energy 33, 3808-3817 (2008).

49. Fu, C. J., Liu, Q. L., Chan, S. H., Ge, X. M. \& Pasciak, G. Effects of transition metal oxides on the densification of thin-film GDC electrolyte and on the performance of intermediate-temperature SOFC. Int. J. Hydrog. Energy 35 11200-11207 (2010)

50. dos Santos-Gómez, L. et al. LSCF-CGO nanocomposite cathodes deposited in a single step by spray-pyrolysis. J. Eur. Ceram. Soc. 38, 1647-1653 (2018).

51. Shimada, $\mathrm{H}$. et al. High power density cell using nanostructured Sr-doped $\mathrm{SmCoO}_{3}$ and $\mathrm{Sm}$-doped $\mathrm{CeO}_{2}$ composite powder synthesized by spray pyrolysis. J. Power Sources 302, 308-314 (2016).

52. Angoua, B. F. \& Slamovich, E. B. Single solution spray pyrolysis of $\mathrm{La}_{0.6} \mathrm{Sr}_{0.4} \mathrm{Co}_{0.2} \mathrm{Fe}_{0.8} \mathrm{O}_{3-\delta^{-}} \mathrm{Ce}_{0.8} \mathrm{Gd}_{0.2} \mathrm{O}_{1.9}$ (LSCF-CGO) Thin film cathodes. Solid State Ion. 212, 10-17 (2012)

53. Garbayo, I. et al. Porous $\mathrm{La}_{0.6} \mathrm{Sr}_{0.4} \mathrm{CoO}_{3-\delta}$ thin film cathodes for large area micro solid oxide fuel cell power generators. J. Power Sources 248, 1042-1049 (2014).

54. Peters, C., Weber, A. \& Ivers-Tiffee, E. Nanoscaled $\left(\mathrm{La}_{0.5} \mathrm{Sr}_{0.5}\right) \mathrm{CoO}_{3-\delta}$ thin film cathodes for SOFC application at $500^{\circ} \mathrm{C}<\mathrm{T}<700{ }^{\circ} \mathrm{C}$. J. Electrochem. Soc. 155, B730-B737 (2008).

55. Hayd, J., Yokokawa, H. \& Ivers-Tiffee, E. Hetero-interfaces at nanoscaled (La, $\mathrm{Sr}) \mathrm{CoO}_{3-\delta}$ thin-film cathodes enhancing oxygen surface-exchange properties. J. Electrochem. Soc. 160, F351-F359 (2013). 


\section{Acknowledgements}

This work was supported by the Advanced Technology Consortium for Solid State Energy Conversion (ASEC). We are grateful to K. Ogasawara and M. Sugasawa for assistance in the PLD and EIS measurements, and N. Saito for the S/TEM measurements. We thank T. Horita and Y. Fujishiro (AIST), K. Yamagiwa (NTK), H. Sumi (Morimura SOFC Technology), H. Ohnishi (Osaka Gas), T. Fujimoto (Kyocera), K. Kobayashi (Denso), and Y. Tanaka (Miura) for their helpful comments and discussion of the results.

\section{Author contributions}

K.D.-B., T.I., H.K., and K.Y. conceptualized the study. K.D.-B. designed and supervised the PLD experiments, prepared the TEM specimens by FIB, carried out SEM observations, and wrote the first draft with additional input from H.S. who carried out the anode-supported cell fabrication and electrochemical measurements. T.I. carried out additional electrochemical measurements with input from K.Y. H.K. and K.Y. helped in the interpretation and analysis of the results. All authors discussed the results and further developed the manuscript.

\section{Competing interests}

The authors declare the following competing interests: a patent application covering this work has been filed by the National Institute of Advanced Industrial Science and Technology to the Japan Patent Office that name K.D.-B., T.I., H.K., and K.Y. as inventors (Application Number: PCT/JP2020/027490; status of application: pending), covering the aspect of manuscript pertaining to the nanocomposite LSCF-GDC and LSC thin-film electrodes prepared via PLD. A patent application covering this work has been filed by the National Institute of Advanced Industrial Science and Technology to the Japan Patent Office that name H.S. (Application Number: 2020-111653; status of application: pending) as an inventor, covering the aspect of manuscript pertaining to the Ni-YSZ anode functional layer prepared via spray pyrolysis technique. There are no other competing interests.

\section{Additional information}

Supplementary information The online version contains supplementary material available at https://doi.org/10.1038/s41467-021-24255-w.

Correspondence and requests for materials should be addressed to K.D.-B.

Peer review information Nature Communications thanks the anonymous reviewers for their contribution to the peer review of this work. Peer reviewer reports are available.

Reprints and permission information is available at http://www.nature.com/reprints

Publisher's note Springer Nature remains neutral with regard to jurisdictional claims in published maps and institutional affiliations.

\begin{abstract}
cc (i) Open Access This article is licensed under a Creative Commons Attribution 4.0 International License, which permits use, sharing, adaptation, distribution and reproduction in any medium or format, as long as you give appropriate credit to the original author(s) and the source, provide a link to the Creative Commons license, and indicate if changes were made. The images or other third party material in this article are included in the article's Creative Commons license, unless indicated otherwise in a credit line to the material. If material is not included in the article's Creative Commons license and your intended use is not permitted by statutory regulation or exceeds the permitted use, you will need to obtain permission directly from the copyright holder. To view a copy of this license, visit http://creativecommons.org/ licenses/by/4.0/.
\end{abstract}

(C) The Author(s) 2021 